\title{
DOCTRINA
}

\section{Cambio climático y planificación urbana: Desafíos y oportunidades para la Evaluación Ambiental Estratégica}

\author{
Climate change and urban planning: Challenges \\ and opportunities for Strategic Environmental Assessment
}

\author{
Robert Currie Ríos \\ Universidad Andrés Bello, Chile \\ Gonzalo Pérez González (iD) \\ Investigador independiente, Chile
}

\begin{abstract}
RESUMEN El cambio climático afecta severamente a las ciudades y sus habitantes. Sus efectos en los centros urbanos - aumento de la temperatura, olas de calor, islas de calor urbanas, desastres naturales, escasez de bienes y alimentos, e inundaciones-impactan en la salud de la población y se ven exacerbados en un contexto de pandemia. En este escenario, los instrumentos que regulan el territorio requieren de una mirada estratégica que permita una planificación urbana que integre la variable climática con el objetivo de reducir la vulnerabilidad y fortalecer la resiliencia de las ciudades, al mismo tiempo que estas contribuyen en la reducción de gases de efecto invernadero. En este sentido, nuestro trabajo examina el marco jurídico de la Evaluación Ambiental Estratégica y el rol que cumple para integrar las diversas visiones sobre el territorio, contribuyendo a lograr una planificación que armonice las distintas escalas territoriales. Asimismo, describimos el apoyo que este instrumento le brinda al órgano responsable para la incorporación de consideraciones de adaptación y mitigación del cambio climático durante el proceso de elaboración del instrumento de ordenamiento territorial respectivo. Finalmente, revisamos algunos desafíos y oportunidades para este instrumento de gestión ambiental, destacando la relevancia de su aplicación transversal a los instrumentos de planificación y ordenamiento territorial, así como el involucramiento activo de la ciudadanía.
\end{abstract}

PALABRAS CLAVE Cambio climático, planificación urbana, evaluación ambiental estratégica, pandemia. 


\begin{abstract}
Climate change severely affects cities and their inhabitants. Its effects on urban centers, such as increase in temperature, heat waves, urban heat islands, natural disasters, shortages of goods and food, and floods, impact the health of the population and are exacerbated in a pandemic context. In this scenario, urban-planning instruments require a strategic view that enables the integration of climate change variables, aimed at reducing vulnerability and strengthen the resilience of cities, while they also contribute to greenhouse gases reduction. In this setting, our work examines the legal framework for Strategic Environmental Assessment and its role in integrating the multiple views on the territory, contributing to achieving land use planning that harmonizes the different territorial scales. Likewise, we describe the support that this environmental management instrument provides to the Responsible Authority in incorporating adaptation and mitigation considerations to climate change during the process of drafting the respective urban planning instrument. Lastly, we review some challenges and opportunities for this environmental management instrument, highlighting the relevance of its application across all land use planning instruments, as well as the active involvement of citizens.
\end{abstract}

KEYWORDS Climate change, urban planning, strategic environmental assessment, pandemic.

\title{
Introducción
}

El cambio climático es el desafío más importante de nuestra era. Frecuentemente se describe que sus efectos están asociados a la sequía, la degradación de ecosistemas, la pérdida de especies, la acidificación de los océanos, los incendios forestales, el derretimiento de glaciares, entre otros fenómenos. Sin embargo, los impactos en los centros urbanos son tanto o más dramáticos que los señalados. El aumento del nivel del mar y las marejadas, el aumento de la temperatura, de los eventos climáticos extremos, de los riesgos de desastres y escasez hídrica, los problemas en la cadena de suministro y conectividad, los daños en infraestructura y la contaminación atmosférica amenazan nuestro modo de vida. En este contexto, es imprescindible que las ciudades incluyan en su planificación la variable climática, aumentando su resiliencia y, en ese proceso, se transformen también en un actor clave en la mitigación de los gases de efecto invernadero.

Los impactos del cambio climático exacerban los desastres y aumentan el riesgo. El Marco de Sendai para la Reducción del Riesgo de Desastres 2015-2030 (UNDRR, 2015), ${ }^{1}$ destaca al cambio climático como uno de los factores subyacentes que aumenta el riesgo de desastres, lo que se suma a otros elementos agravantes, como lo son

1. Adoptado en la Tercera Conferencia Mundial de las Naciones Unidas sobre el Riesgo de Desastres, celebrada entre el 14 al 18 de marzo de 2015, en Sendai, Japón. 
las pandemias y epidemias. A mayor abundamiento, el Grupo Intergubernamental de Expertos sobre el Cambio Climático (IPCC, por su nombre en inglés) ha señalado que hay buena evidencia de que las temperaturas extremas (cálidas y frías) afectan la salud, particularmente los índices de mortalidad (IPCC, 2018: 556).

Lograr ciudades resilientes cobra particular relevancia en contexto de pandemia. $\mathrm{Al}$ respecto, cabe preguntarse por el rol que juega el cambio climático y la planificación urbana en dichos escenarios. Se pueden encontrar diversas interacciones, como el efecto multiplicador de riesgo de desastres, la propagación de enfermedades asociadas a eventos climáticos, como lo son las enfermedades transmitidas por el agua, y la contaminación atmosférica como agravante de las consecuencias de pandemias.

Es relevante detenerse sobre este último punto, especialmente en relación con la pandemia originada por el SARS-CoV-2, causante de la enfermedad coronavirus (covid-19). Múltiples estudios han investigado la relación entre la contaminación atmosférica y su incidencia en las consecuencias del covid-19, revelando que la exposición al material particulado fino, es decir, inferior a 2,5 micrones, exacerban los efectos de esta enfermedad. Uno de esos estudios, realizado por investigadores de la Universidad de Harvard, concluyó que un pequeño incremento en la exposición a largo plazo a MP2,5 lleva a un gran incremento en el índice de mortalidad del covid-19 (Wu y otros, 2020: 2).

Lo anterior es particularmente relevante para Chile, que es altamente vulnerable a los impactos del cambio climático. De hecho, cumple con siete de los nueve criterios de vulnerabilidad establecidos por la Convención Marco de Naciones Unidas para el Cambio Climático (CMNUCC). Uno de ellos es, precisamente, el de contar con zonas de alta contaminación atmosférica urbana (IPCC, 2018: 556), lo que trae aparejado múltiples consecuencias para la salud de las personas, entre las que ahora también podemos incluir la exacerbación de los efectos del covid-19. Por tanto, es imprescindible diseñar ciudades más resilientes para enfrentar los efectos del cambio climático y, también, para aplacar las consecuencias y propagación de esta y otras pandemias en el futuro.

El rol de las ciudades en materia de cambio climático es fundamental. Según datos de Naciones Unidas, el 55\% de la población mundial vive en áreas urbanas, tasa que llega al 81\% en América Latina y el Caribe. ${ }^{2}$ Dichas ciudades cada día son afectadas en mayor medida por los efectos del cambio climático y, al mismo tiempo, constituyen una de las principales causantes de este fenómeno global. De hecho, son estos espacios los que consumen el $78 \%$ de la energía del planeta y generan el 70\% de las emisiones de gases de efecto invernadero (Comité Científico COP25, 2019: 12). De ahí la importancia de generar una gestión del territorio adecuada, tanto para la adaptación

2. United Nations, «68\% of the world population projected to live in urban areas by 2050 , says UN», 16 de mayo de 2018, disponible https://bit.ly/3EvtYmK. 
a los efectos del cambio climático, como para la mitigación de los gases que generan dicho fenómeno.

Para una planificación urbana adecuada existe una multiplicidad de instrumentos de carácter político y regulatorio, que pueden ser indicativos o vinculantes. Por tanto, enfocarse en abordar la problemática mediante los instrumentos adecuados, y su debida coordinación, es esencial para internalizar la variable climática en la proyección territorial.

Los instrumentos de planificación territorial, por su carácter urbano y vinculante, tienen un rol fundamental en el proceso de incorporación de la variable climática en la planificación urbana. Dichos instrumentos deben formularse y elaborarse estratégicamente, de manera de «mejorar la calidad del aire, impulsando ciudades más compactas, con sistemas de transporte sustentable, uso eficiente de la energía y de la infraestructura, disminución y manejo adecuado de residuos, y espacios públicos de calidad, entre otros elementos, que contribuyan a disminuir los efectos del cambio climático» (Gobierno de Chile, 2016: 33). Al respecto, cabe preguntarse cómo estos instrumentos de planificación pueden tener una mirada omnicomprensiva que permita integrar la variable climática. La respuesta está dada por un instrumento de gestión ambiental que cada día cobra mayor relevancia, este es, la Evaluación Ambiental Estratégica (EAE).

La EAE es un procedimiento realizado por el organismo público respectivo, en coordinación con el Ministerio del Medio Ambiente, y que busca incorporar consideraciones ambientales de desarrollo sustentable en la etapa inicial de formulación de las políticas y planes de carácter normativo general, que tengan impacto sobre el medio ambiente o la sustentabilidad. Lo anterior, identificando obstáculos, factores críticos de decisión y evaluando alternativas u opciones de desarrollo que permitan políticas y planes adecuados. Asimismo, estos procesos consideran la participación de múltiples actores, lo que redunda en la integración de diversas miradas para una planificación completa e integradora.

El uso e importancia de la EAE se ha fortalecido en los últimos años, dado el mandato establecido en el artículo 7 bis de la Ley 19.300 sobre Bases Generales del Medio Ambiente, que hace su aplicación obligatoria para una serie de instrumentos de planificación y ordenamiento territorial.

A mayor abundamiento, su uso ha aumentado incluso cuando su aplicación es eminentemente discrecional. Estos últimos casos corresponden a aquellos en que el sometimiento a la EAE depende del Presidente de la República, luego de ser propuesto por el Consejo de Ministros para la Sustentabilidad, como es el caso de las políticas y planes de carácter normativo general que tengan impacto sobre el medio ambiente o la sustentabilidad. De estos instrumentos, actualmente se han sometido a EAE la Política Energética Nacional 2050 y la Política Nacional de Ordenamiento Territorial. 
Asimismo, están en proceso de elaboración otros instrumentos que serán evaluados bajo el procedimiento de la EAE, estos son, el Plan Nacional de Construcción Sustentable, la Política Nacional de Minería, la Actualización de la Política Energética Nacional 2050 y la Actualización de la Política Nacional de Uso del Borde Costero.

La relevancia de la EAE y su interacción con el cambio climático se ve reflejada también en las iniciativas legales en la materia. El Proyecto de Ley Marco de Cambio Climático establece en su artículo 39 que los instrumentos de ordenamiento y planificación territorial incorporarán consideraciones ambientales del desarrollo sustentable relativas a la mitigación y adaptación al cambio climático mediante la EAE. ${ }^{3}$

Por lo expuesto, cobra particular relevancia analizar el rol que cumple la EAE en la incorporación de la variable climática en la planificación urbana. En este orden de ideas, nuestro artículo realiza una revisión de múltiples impactos del cambio climático en las ciudades, de manera de contextualizar la incidencia de dichos impactos en los centros urbanos, así como la impostergable necesidad de que sean considerados y abordados por los instrumentos de planificación territorial. Luego, realizamos un análisis de los instrumentos de ordenamiento y planificación territorial con incidencia en los centros urbanos, discutiendo sobre la necesidad de superar la regulación del territorio para pasar a su planificación, lo que solo se puede lograr mediante un instrumento transversal y articulador como lo es la EAE. Posteriormente, revisamos los alcances de la EAE como instrumento de gestión ambiental y los mecanismos para integrar la variable climática en los instrumentos de planificación territorial, para finalmente concluir identificando algunas oportunidades y desafíos para la EAE en un contexto de cambio climático.

\section{Los impactos del cambio climático en las ciudades}

Los efectos del cambio climático son particularmente relevantes para nuestro país, dada su vulnerabilidad. Al respecto, cabe tener presente los siete criterios de vulnerabilidad establecidos por la CMNUCC que presenta Chile, a saber: áreas costeras de baja altura; zonas áridas y semiáridas, zonas con cobertura forestal y zonas expuestas al deterioro forestal; zonas propensas a los desastres naturales; zonas expuestas a la sequía y a la desertificación; zonas de alta contaminación atmosférica urbana; y zonas de ecosistemas frágiles, incluidos los ecosistemas montañosos. Como se puede observar, varios de estos criterios atañen directamente a las ciudades, lo que sumado al hecho de que en Chile cerca del 90\% de la población es urbana (Gobierno de Chile,

3. Boletín 13.191-12, Proyecto de Ley Marco de Cambio Climático. El artículo 39 del Proyecto de Ley Marco de Cambio Climático señala: «Mediante la Evaluación Ambiental Estratégica los instrumentos de ordenamiento y planificación territorial incorporarán consideraciones ambientales del desarrollo sustentable relativas a la mitigación y adaptación al cambio climático». 
2018: 5), pone de relieve la urgencia de actuar en la materia, mediante los instrumentos apropiados.

Como adelantábamos, las ciudades cumplen un rol primordial en la mitigación y adaptación al cambio climático. Por ello, en el plano internacional el foco de las discusiones se ha empezado a dirigir a estos espacios, y se ha generado mayor literatura e investigación, así como el compromiso del IPCC de publicar un informe especial sobre ciudades en el sexto Informe de Evaluación (AR6) (Gobierno de Chile, 2018: 15).

Por otra parte, cabe mencionar que los efectos que se verán en esta sección son un resumen de los más importantes, entendiendo que se generan muchos más y que el cambio climático opera como un multiplicador de amenazas, conflictos y desastres.

También se debe tener en cuenta que la vulnerabilidad a los efectos del cambio climático varía en función de factores geográficos, económicos y sociales, como la pobreza y marginalidad, que inciden en asentamientos informales carentes de infraestructura urbana, así como en comunidades que viven en lugares más expuestos a áreas de riesgo (Gobierno de Chile, 2018: 13), razón por cual los impactos aquí descritos se generarán con más intensidad en aquellos centros urbanos con mayor inequidad territorial.

A continuación, examinamos algunos de los impactos más significativos del cambio climático sobre las ciudades.

\section{Aumento del nivel del mar y marejadas}

Este es uno de los impactos más evidentes y estudiados, dada la gran cantidad de ciudades costeras alrededor del mundo. Las proyecciones del IPCC indican que para el final del siglo el aumento del nivel del mar puede llegar hasta casi un metro (IPCC, 2018: 554).

De confirmarse estas proyecciones, las consecuencias serían devastadoras. Sin perjuicio de lo señalado, ya en la actualidad podemos percibir múltiples impactos como consecuencia del aumento del nivel del mar y las marejadas, como inundaciones, erosión costera, pérdida de humedales y daños en infraestructura.

Adicionalmente, cabe destacar que las pérdidas económicas son millonarias. Podemos tomar de ejemplo a la ciudad de Valparaíso, donde la Evaluación Económica del Plan de Acción Nacional de Cambio Climático del año 2015 indica que las pérdidas por inactividad del puerto de dicha ciudad como consecuencia del aumento del nivel del mar oscilarían entre 36 y más de 100 millones de dólares diarios (Gobierno de Chile, 2018: 21). 


\section{Temperaturas elevadas, olas de calor e islas de calor urbanas}

El aumento de la temperatura a nivel global se ve potenciado en los centros urbanos. El IPCC proyecta que, para mediados de siglo, la mayoría de la población que vive en grandes centros urbanos estará expuesta a un aumento mínimo de $2{ }^{\circ} \mathrm{C}$ sobre los niveles preindustriales. Asimismo, se estima que para el final del siglo este aumento puede ser de hasta $4{ }^{\circ} \mathrm{C}$ en algunas ciudades (IPCC, 2018: 554).

Sumado a las altas temperaturas, encontramos las olas de calor. Según la Dirección Meteorológica de Chile, las olas de calor diurnas se producen toda vez que la temperatura máxima diaria supere el percentil 90 diario de distribución histórica, por tres días consecutivos en cualquier época del año (Dirección Meteorológica de Chile, 2020). Las principales causas de enfermedades y muertes durante olas de calor son enfermedades respiratorias y cardiovasculares rodean (Public Health England, 2015: 2). La mayoría de las personas que mueren durante una ola de calor son aquellas que presentan enfermedades crónicas (sobre todo cardiopatías, enfermedades pulmonares y renales), que son agravadas como efecto del calor. Además, el calor tiene el potencial de generar accidentes cerebrovasculares por formación de coágulos (OPS, 2019: 2). Al respecto, cabe hacer presente que las olas de calor son más intensas en las ciudades que en las áreas rurales que la rodean (Public Health England, 2015: 12), lo que se ve exacerbado por las islas de calor urbanas.

Las islas de calor urbanas consisten en las diferencias de temperaturas entre los distintos espacios construidos y sus alrededores como resultado de la modificación en la cobertura del suelo y las actividades urbanas, como el transporte motorizado y actividades industriales, que mediante las emisiones térmicas contribuyen al calentamiento urbano (Gobierno de Chile, 2018: 15).

Las islas de calor urbanas potencian los efectos de aumento de temperatura en las ciudades en general, y los eventos de olas de calor, en particular. Estudios recientes evidencian la presencia de estas islas en todas las ciudades principales de Chile, con intensidades máximas que van desde $2{ }^{\circ} \mathrm{C}$ a $10{ }^{\circ} \mathrm{C}$ (Comité Científico COP25: 30).

Los impactos descritos son especialmente nocivos en aquellas ciudades que no cuentan con infraestructura que permita soportar las altas temperaturas. La pobreza y la marginalidad contribuyen a esta vulnerabilidad rodean (Public Health England, 2015: 13).

Los efectos en la salud de las personas producto de las altas temperaturas, olas de calor e islas de calor urbanas son significativos. La evaluación económica del Plan de Acción Nacional de Cambio Climático de 2015 señalada previamente, determinó que la Región Metropolitana - en una proyección hacia finales del presente siglo- tendría una mortalidad entre cuatro y catorce mil personas al año como causa directa e indirecta de temperaturas elevadas rodean (Public Health England, 2015: 21). 


\section{Eventos climáticos extremos}

La frecuencia e intensidad de los eventos climáticos extremos ha aumentado sostenidamente en las últimas décadas. Las olas de calor descritas previamente, las tormentas y las inundaciones son cada vez más frecuentes e intensas en las ciudades. Por ejemplo, las inundaciones ya no solo se generan en ciudades costeras, sino en aquellas que se encuentran en el interior, producto del aumento en la intensidad de las lluvias y la falta de sistemas de drenaje urbanos adecuados y problemas con los sistemas de alcantarillado (IPCC, 2018: 556). Esto también puede llevar a la contaminación de fuentes de agua y al aumento de enfermedades transmitidas por el agua (IPCC, 2018: 556).

\section{Aumento del riesgo de desastres}

El cambio climático puede aumentar el riesgo de desastres asociados a algunas amenazas, tanto de origen natural como antrópico, como la ocurrencia e intensidad de eventos hidrometeorológicos extremos (marejadas, olas de calor, sequías, precipitación intensa y sus efectos derivados como alud, aluvión, desbordes, inundaciones, entre otros), la probabilidad de ocurrencia de incendios forestales y las emergencias sanitarias que podrían ser aumentadas por efectos del clima (MMA, 2020: 10).

En este contexto, el Marco de Sendai para la Reducción del Riesgo de Desastres 2015-2030 dispone que deben adoptarse medidas más específicas para luchar contra los factores subyacentes que aumentan el riesgo de desastres, como las consecuencias de la pobreza y la desigualdad, el cambio climático y la variabilidad del clima, y la urbanización rápida y no planificada (UNDRR, 2015: 10).

\section{Suministro de bienes y alimentos}

Diversos estudios de casos demuestran cómo el clima extremo puede impedir actividades económicas, dañar infraestructura industrial e interrumpir la cadena de suministro (IPCC, 2018; 556). De esta manera, impactos secundarios del cambio climático afectan tres actividades de la cadena de valor: el suministro, la producción y la distribución (Aylwin Fernández y Currie Ríos, 2020: 7-37).

Esto es particularmente relevante por la escasez de bienes y alimentos que pueden generarse en la ciudad, así por el incremento de los precios. Por tanto, cuando se busca adaptar los sistemas alimentarios urbanos se requieren cambios radicales en la producción, almacenamiento, procesamiento y cadena de suministro (IPCC, 2018: 568). 


\section{Infraestructura}

La infraestructura de las ciudades se verá impactada por eventos climáticos extremos y afectará los sistemas urbanos interconectados. Estos efectos serán especialmente evidentes en los sectores de recursos hídricos, sanitización, energía, transportes y comunicaciones (IPCC, 2018: 568).

Preservar la integridad de la infraestructura urbana es esencial para el soporte de las actividades y servicios de la ciudad, muchos de estos clave para la preservación de la salud de las personas, los bienes y modos de subsistencia (Gobierno de Chile, 2018: 34).

\section{Escasez hídrica}

Los efectos de la sequía generan escasez de recursos hídricos, problemas en el suministro de electricidad cuando esta es generada por centrales hidroeléctricas, aumento en el precio de los alimentos e inseguridad alimentaria por la reducción de proveedores (IPCC, 2018: 555).

Como es lógico, este impacto se presenta con mayor intensidad en las ciudades localizadas en regiones áridas o semiáridas, lo que, en el caso de Sudamérica, se ve exacerbado por el retroceso de los glaciares que son fuente de agua para las ciudades andinas (Gobierno de Chile, 2018: 8).

\section{Contaminación atmosférica}

La calidad del aire en las ciudades puede verse afectada por el cambio climático. La Agencia de Protección Ambiental (EPA, por su nombre en inglés) de Estados Unidos ha señalado que el calentamiento atmosférico asociado con el cambio climático tiene el potencial de incrementar el nivel de ozono troposférico (EPA, 2019).

En el mismo sentido, el IPCC ha señalado que el aumento de la frecuencia de los días calurosos y los periodos cálidos exacerbará los efectos de las isla de calor, que causan problemas de salud relacionados con el calor y, posiblemente, un aumento de la contaminación del aire (IPCC, 2018: 554).

Por otra parte, la Evaluación Nacional del Clima de Estados Unidos indica que el cambio climático afectará la salud humana al aumentar el ozono troposférico y el material particulado en algunos lugares. Al respecto, cabe recordar que ambos contaminantes son especialmente nocivos para la salud de las personas. Por ejemplo, el ozono troposférico está asociado con disminución de la función pulmonar, el aumento de ingresos hospitalarios y a las salas de emergencia por asma, y aumento de muertes prematuras. ${ }^{4}$

4. Centers for Disease Control and Prevetion, «Climate Change decreases the quality of the air we breathe», disponible https://bit.ly/3FulAVM. 
Este tipo de contaminación se da preeminentemente en los centros urbanos. En este sentido, cabe señalar que la cueca de Santiago se encuentra saturada tanto por ozono troposférico como por material particulado, razón por la cual se dictó el Decreto Supremo 31, de 2016, del Ministerio del Medio Ambiente que establece el Plan de Prevención y Descontaminación Atmosférica para la Región Metropolitana de Santiago, que tiene el objetivo, entre otros, de cumplir las normas de calidad ambiental para ozono y material particulado.

Respecto al ozono, el Plan señalado va en la misma línea de los párrafos anteriores, indicando que, durante el periodo estival, el calentamiento superficial permite la erosión de la capa de inversión térmica sobre la cuenca, lo que se traduce en un mejoramiento significativo de la ventilación. Sin embargo, la emisión de compuestos nitrogenados y de compuestos orgánicos, más la disponibilidad de radiación solar, favorecen la formación de compuestos fotoquímicos, generando el aumento en las concentraciones de ozono troposférico. ${ }^{5}$

Finalmente, el Plan también identifica como un co-beneficio asociado al cambio climático, la reducción del carbono negro. Este último es un contaminante climático de vida corta, que forma parte del material particulado, y que se forma como resultado de la combustión incompleta de combustibles fósiles (diésel, petróleos pesados y carbón) y de la leña. El carbono negro se ha identificado como unas de las causas del deshielo de los polos y de la nieve de las montañas (Comité Científico COP25, 2019: 7), por lo que su disminución acarrea efectos positivos tanto para la salud de las personas como para la lucha contra el cambio climático. En este orden de ideas, en la actualización del año 2020 de la Contribución Determinada a Nivel Nacional, Chile comprometió una reducción de al menos un $25 \%$ de las emisiones totales de carbono negro al 2030, con respecto al año 2016 (MMA, 2020: 35).

Para hacerse cargo de estos impactos es imprescindible contar con ciudades adaptadas a su entorno y características propias, incluyendo una gestión territorial que tome medidas para reducir su vulnerabilidad, fortalecer su resiliencia y mitigar el cambio climático.

Para transformar las ciudades al tenor de lo expresado, es necesario incorporar la variable climática en los instrumentos de planificación territorial. Son precisamente estos instrumentos los que tienen la capacidad de ordenar los espacios urbanos de manera de evitar o atenuar los impactos del cambio climático descritos en este capítulo. Antes de revisar cómo se diseña el proceso de incorporación de la variable climática a la planificación de las ciudades, es pertinente hacer una revisión de los instrumentos con los que dispone nuestro ordenamiento jurídico para dichos efectos.

5. Decreto Supremo 31, de 2016, del Ministerio del Medio Ambiente que establece el Plan de Prevención y Descontaminación Atmosférica para la Región Metropolitana de Santiago. I.2.2. Antecedentes meteorológicos. 


\section{Instrumentos de ordenamiento y planificación territorial que inciden en las ciudades}

Los instrumentos de ordenamiento territorial son «todas aquellas normas, planes o estrategias que condicionan y/o direccionan la acción de transformación de los agentes públicos y privados sobre el territorio» (Pretch Rorris, Reyes Paecke y Salamanca Gatica, 2016: 25). Esta es una concepción amplia de los instrumentos de ordenamiento territorial, pues involucra todos aquellos instrumentos que tengan alguna influencia sobre el territorio.

En dicho sentido Pretch Rorris, Reyes Paecke y Salamanca Gatica (2016) presentan una buena clasificación de estos instrumentos basado en la intencionalidad y objetivos que persigue el instrumento en cuestión, distinguiendo aquellos que tienen finalidad planificadora de aquellos que tienen una finalidad de protección de un recurso natural, cultural u otro. ${ }^{6}$

Los primeros son aquellos procesos racionales de toma de decisión, basados en un diagnóstico de la realidad con miras a generar una distribución espacial de los usos del suelo, en conformidad con los objetivos de desarrollo económico y social, que se denominan instrumentos de ordenamiento territorial estrictos, los cuales pueden ser a su vez normativos o indicativos, dependiendo de su carácter vinculante. Mientras que los segundos son aquellos entendidos como «zonificaciones sujetas a protección especial».?

En este contexto, revisaremos los instrumentos de ordenamiento territorial estrictos, tanto normativos como indicativos. Los normativos regulan de manera vinculante a las zonas urbanas, incluyendo, por ejemplo, reglas específicas sobre la densidad y altura máxima de una construcción, la morfología de la ciudad y los usos de suelo del territorio o zonificación, determinando las regulaciones por las cuales se construirá la ciudad en lo sucesivo, lo que significa una gran oportunidad para integrar la variable climática en la planificación de las ciudades. No obstante, dichos instrumentos no logran un efecto significativo en el establecimiento de normas de constructibilidad y características urbanísticas en materia climática, debido a que carecen de instancias de interacción con otros instrumentos que planifican el desarrollo del territorio, según analizaremos más adelante.

Por otra parte, los instrumentos de ordenamiento territorial indicativos, sin per-

6. Dentro de las zonas de protección especial, se incluyen aquellas que apuntan a: i) la diversidad biológica y valor ambiental del territorio, ii) el patrimonio cultural, iii) las comunidades indígenas, y iv) el turismo.

7. En dicho sentido, independiente de la clasificación de los instrumentos de ordenamiento territorial, existen circunstancias transversales a todos o algunos de estos instrumentos, entre las que se pueden destacar principalmente dos: la EAE y la participación de los pueblos indígenas en el caso de la consulta indígena. 
juicio de no ser vinculantes, se relacionan con el funcionamiento y estructura de los núcleos urbanos, y son también instrumentos relevantes de revisar por su incidencia en materia de cambio climático, particularmente en lo relativo a la interrelación entre lo rural y lo urbano.

Finalmente, hacemos algunas reflexiones sobre regulación versus planificación del territorio y enunciamos lo que desarrollamos en las secciones siguientes, esto es, el rol que cumple la EAE como instrumento de gestión ambiental que contribuye a la incorporación de medidas que apunten a fines que trasciendan a los meramente reguladores del territorio, con una mirada integradora de diversos instrumentos en múltiples escalas y con el claro objetivo de apoyar el proceso de ciudades adaptadas y resilientes al cambio climático y que, además, contribuyan a la mitigación de los gases de efecto invernadero.

\section{Instrumentos de ordenamiento territorial normativos}

Las ciudades en Chile se rigen por instrumentos de ordenamiento territorial estrictos de carácter normativo, que corresponden a los instrumentos de planificación territorial definidos por la Ley General de Urbanismo y Construcciones (LGUC), esto es, aquellos cuyas disposiciones son vinculantes para todo aquel que quiera realizar una obra, proyecto o actividad en el área regulada. Por tanto, la normativa que se establece mediante estos instrumentos es de cumplimiento obligatorio, con sanciones en caso de incumplimiento y es verdaderamente una «regulación del territorio», esto es, de usos de suelo, con exigencias claras para el desarrollo de los territorios urbanos, a diferencia de los otros instrumentos que son solo referenciales o indicativos, según se explicará más adelante.

Sin perjuicio de lo señalado, y como adelantamos, la falta de instancias de interacción con otros instrumentos que inciden en el territorio atenta contra su adecuada planificación. Esto es particularmente notorio en materia de cambio climático, toda vez que estos instrumentos presentan algunas deficiencias, como: i) ausencia de variables o metas ambientales explícitas asociadas al cambio climático; ii) limitadas herramientas para reconocer e incorporar zonas o elementos de valor natural, debido a las restricciones normativas existentes en la zonificación; iii) falta de mecanismos adecuados para planificar y regular las áreas periféricas de las ciudades, donde convive lo urbano y lo rural; $y$ iv) carencia de facultades para proteger ecosistemas relevantes al interior de las ciudades y centros poblados.

En este contexto, y para comprender el alcance de estos instrumentos, revisaremos someramente los instrumentos de planificación territorial definidos por la LGUC, que son: el Plan Regulador Intercomunal, el Plan Regulador Metropolitano, 
el Plan Regulador Comunal, el Plan Seccional, y el Límite Urbano. ${ }^{8}$ Estos instrumentos regulan de forma vinculante el «territorio urbano», entendiendo por tal aquel que se encuentra dentro del límite urbano.

\section{Planificación urbana intercomunal (planes regionales intercomunales y metropolitanos)}

Respecto a los planes reguladores intercomunales y los planes reguladores metropolitanos, ${ }^{9}$ la LGUC dispone que «la planificación Urbana Intercomunal se realizará por medio del Plan Regulador Intercomunal (PRI) o del Plan Regulador Metropolitano (PRM), en su caso, instrumentos constituidos por un conjunto de normas y acciones para orientar y regular el desarrollo físico del área correspondiente». ${ }^{10}$ Ambos instrumentos corresponden al nivel intercomunal de planificación y regulan el desarrollo físico de las áreas urbanas y rurales de diversas comunas que, por sus relaciones, se integran en una unidad urbana.

Cabe tener presente que, si bien hemos señalado con anterioridad que los instrumentos de planificación territorial solo son capaces de regular el territorio urbano, tanto los planes reguladores intercomunales y los planes metropolitanos son capaces de generar un tipo de regulación (no fijando usos de suelo) sobre el territorio rural, circunstancia que ha sido reconocida expresamente por la Contraloría General de la República. ${ }^{11}$ Lo anterior contribuye a coordinar el territorio, como con lo son las zonas de extensión urbana, que contribuirán en una planificación que debe tener en miras los impactos del cambio climático. Por tanto, este instrumento tiene importantes efectos sobre las ciudades, pero se adscribe a territorios más amplios.

8. Decreto con Fuerza de Ley 458, de 1975, del Ministerio de Vivienda y Urbanismo, aprueba una nueva Ley General de Urbanismo y Construcciones. Capítulo 2, párrafo 3 y siguientes.

9. La diferencia entre un plan intercomunal de uno metropolitano es únicamente la cantidad de población a la cual se aplica el instrumento. La misma LGUC señala en su artículo 34: «Cuando esta unidad sobrepase los 500.00o habitantes, le corresponderá la categoría de área metropolitana para los efectos de su planificación. La Planificación Urbana Intercomunal se realizará por medio del Plan Regulador Intercomunal o del Plan Regulador Metropolitano, en su caso, instrumentos constituidos por un conjunto de normas y acciones para orientar y regular el desarrollo físico del área correspondiente».

10. Decreto con Fuerza de Ley 458, de 1975, del Ministerio de Vivienda y Urbanismo, que aprobó la Ley General de Urbanismo y Construcciones.

11. El Dictamen 37.731, de 2007, de Contraloría General de la República, el citado artículo 55 establece un procedimiento que debe seguirse en cada situación particular respecto de las construcciones en el área rural, en las que tratándose de áreas rurales afectas a planificación territorial —como ocurre en la especie-, supone la consideración de los usos de suelo que el respectivo instrumento contemple. 


\section{Plan Regulador Comunal}

Consagrado en la LGUC y regulado también en la Ordenanza General de Urbanismo y Construcciones, el Plan Regulador Comunal constituye el principal instrumento de planificación a nivel comunal, sin embargo, su acción se encuentra limitada solo al ámbito urbano. Este instrumento es elaborado por la municipalidad, que es la institución competente en el nivel comunal de la planificación.

El artículo 41 de la LGUC define esta escala de planificación señalando que es «aquella que promueve el desarrollo armónico del territorio comunal, en especial de sus centros poblados, en concordancia con las metas regionales de desarrollo económico-social. La planificación urbana comunal se realizará por medio del Plan Regulador Comunal».

\section{Plan Seccional}

Este es un instrumento de planificación equivalente al Plan Regulador Comunal, pero cuyo ámbito de aplicación territorial es menor. Es decir, abarca solo una parte del área urbana comunal. Este instrumento no debe confundirse con el Plano Seccional, que es un instrumento que permite la aplicación de algunas disposiciones de algunas disposiciones del Plan Regulador Comunal que requieren de estudios más detallados. ${ }^{12}$

\section{Límite Urbano}

Establecido en la LGUC y definido como instrumento de planificación territorial por la Ordenanza General de Urbanismo y Construcciones, el límite urbano es el más básico de los instrumentos de planificación y consiste en una línea imaginaria que delimita las áreas urbanas y de extensión urbana que conforman los centros poblados, diferenciándolos del resto del área comunal. ${ }^{13}$

Como podemos observar de la breve revisión de los instrumentos de planificación territorial, estos orientan el desarrollo del territorio y permiten determinar qué y dónde se puede construir, y son determinantes en la interacción de los espacios urbanos y, consecuentemente, inciden sobre la población. Circunstancias como la densidad poblacional, la altura máxima de una construcción, la distancia entre viviendas

12. Decreto con Fuerza de Ley 458, de 1975, del Ministerio de Vivienda y Urbanismo: «Se entenderá por límite urbano, para los efectos de la presente ley y de la Ley Orgánica de Municipalidades, la línea imaginaria que delimita las áreas urbanas y de extensión urbana que conforman los centros poblados, diferenciándolos del resto del área comunal».

13. Artículo 52 del Decreto con Fuerza de Ley 458, de 1975, del Ministerio de Vivienda y Urbanismo, aprueba una nueva Ley General de Urbanismo y Construcciones 
y equipamientos, la instalación de energías alternativas en las construcciones, e incluso, la instalación de la urbanización, resultan cruciales cuando nos referimos a la implementación de medidas de mitigación o adaptación al cambio climático.

\section{Instrumentos de ordenamiento territorial indicativos}

Corresponden a aquellos instrumentos que fijan lineamientos para la planificación territorial en general, relativos a las áreas urbanas y rurales, pero cuyas disposiciones no son obligatorias para los particulares. En dicho sentido, su incumplimiento no acarrea sanciones para los privados, ya que están formulados con el objetivo de orientar las decisiones formales que debe adoptar la autoridad en el ejercicio de sus funciones.

Sin perjuicio de lo anterior, es relevante revisar estos instrumentos por tres motivos: i) la inexorable interrelación entre los núcleos urbanos con sus áreas rurales colindantes, toda vez que resulta innegable que las ciudades como organismos complejos se proveen desde las zonas rurales y ambas se retroalimentan mutuamente; ii) al ser considerados en la confección de los instrumentos de planificación territorial, se pueden lograr efectos sinérgicos más eficientes y efectivos sobre el territorio; y iii) la posibilidad que tienen de contribuir a la mitigación y adaptación al cambio climático. Los instrumentos indicativos más importantes son los que siguen.

\section{Plan Regional de Ordenamiento Territorial}

El artículo 17 letra a) de la Ley 19.175 Orgánica Constitucional sobre Gobierno y Administración Regional, que fue modificada por la Ley 21.074, sobre Fortalecimiento a la Regionalización del país, define el Plan Regional de Ordenamiento Territorial como un instrumento que orienta la utilización del territorio de la región para lograr su desarrollo sustentable a través de lineamientos estratégicos y una macro zonificación de dicho territorio. Adicionalmente, cobra particular relevancia que este instrumento tenga la función de establecer, con carácter vinculante, condiciones de localización para la disposición de los distintos tipos de residuos y sus sistemas de tratamientos y condiciones para la localización de las infraestructuras y actividades productivas en zonas no comprendidas en la planificación urbanística, junto con la identificación de las áreas para su localización preferente. ${ }^{14}$

Por tanto, este instrumento interviene de una forma importante en el territorio rural al establecer, con carácter vinculante, condiciones de localización para diversas actividades. Así, el Plan Regional de Ordenamiento Territorial es una nueva herra-

14. Artículo 17 letra a) de la Ley 19.175, Orgánica Constitucional sobre Gobierno y Administración Regional 
mienta que puede llegar a ser muy relevante cuando finalmente se implemente. Al respecto, cabe recordar que su elaboración se encuentra sujeta a la Política Nacional de Ordenamiento Territorial. ${ }^{15}$

En este orden de ideas, el Plan Regional de Ordenamiento Territorial puede influir significativamente en la confección y revisión de los instrumentos de planificación territorial al indicar zonas específicas para el desarrollo de ciertas actividades, como, por ejemplo, que las zonas agrícolas o productoras de alimentos para las ciudades se encuentren cercanas a infraestructura de transporte, reduciendo el traslado a los centros de distribución urbana. Esto representaría una medida que ayudaría a enfrentar impactos del cambio climático en las ciudades, como lo son los problemas en la cadena de distribución y suministro y, a su vez, permitiría reducir la emisión de gases de efecto invernadero, aportando en la mitigación climática.

Otro ejemplo es que el Plan Regional de Ordenamiento Territorial podría establecer usos preferentes en zonas aledañas a los desarrollos urbanos, de manera que puedan actuar como «zonas buffer» contra efectos perniciosos del cambio climático, como bosques interurbanos, entre muchos otros.

\section{Zonificación de Uso del Borde Costero}

En términos generales, la Zonificación del Uso del Borde Costero tiene como objetivo realizar un ordenamiento de los usos del territorio costero, compatibilizando distintos intereses y planificando sus usos, mediante un proceso que incluye la participación ciudadana.

El marco legal de este instrumento se encuentra en el Decreto Supremo 475, de 1994, del Ministerio de Defensa Nacional, Subsecretaría de Marina, ${ }^{16}$ que establece la Política Nacional de Uso del Borde Costero del Litoral de la República y crea la Comisión Nacional de Uso del Borde Costero del Litoral.

De igual modo que con el Plan Regional de Ordenamiento Territorial, se reconoce la importancia de este instrumento en la Ley 19.175 Orgánica Constitucional sobre Gobierno y Administración Regional, que fue modificada por la Ley 21.074, sobre Fortalecimiento a la Regionalización del país, cuando señala:

El gobierno regional deberá proponer un proyecto de zonificación del borde costero de la región, así como las eventuales modificaciones a la zonificación vigente,

15. El artículo 17 letra a) de la Ley 19.175 dispone que le corresponderá al Gobierno Regional «elaborar y aprobar el plan regional de ordenamiento territorial en coherencia con la estrategia regional de desarrollo y la política nacional de ordenamiento territorial, previo informe favorable de los ministros que conforman la Comisión Interministerial de Ciudad, Vivienda y Territorio establecida en el párrafo quinto de este literal».

16. Actual Subsecretaria para las Fuerzas Armadas. 
en concordancia con la política nacional existente en la materia. Dicha zonificación deberá ser aprobada mediante decreto supremo expedido a través del Ministerio de Defensa Nacional y será reconocida en el respectivo plan regional de ordenamiento territorial. ${ }^{17}$

Al igual que con el Plan Regional de Ordenamiento Territorial, este instrumento, que en el caso de las áreas urbanas se superpone con los instrumentos de planificación territorial, puede servir para integrar medidas eficientes sobre la regulación de un mismo territorio. Por ejemplo, respecto de la infraestructura portuaria, puede traducirse en la construcción de estructuras que permitan el movimiento de los vientos desde el núcleo urbano al borde costero y viceversa, de modo de disminuir la temperatura de las ciudades costeras, contribuyendo a enfrentar uno de los efectos del cambio climático más significativo en las ciudades.

\section{Manejo Integrado de Cuencas}

El Manejo Integrado de Cuencas se ha definido como un instrumento que describe «un área geográfica cuyas aguas superficiales vierten a una red hidrográfica común, constituyéndose a su vez un cauce que puede desembocar en un río principal, lago y/o directamente al mar» (Pérez Castillo y Shinomi, 2009: 3). Por tanto, representa una herramienta clave para entender la relación de las ciudades con sus provisiones de agua, tanto en relación con las reservas de agua potable para consumo, descarga de desechos de diversos tipos, y los impactos de la ocupación humana sobre los servicios ecosistémicos colindantes.

La Dirección General de Aguas es la encargada de implementar este instrumento, según las disposiciones contenidas en el Código de Aguas. Sin embargo, a la fecha no ha sido debidamente incorporado dentro de nuestro ordenamiento jurídico, toda vez que existe una gran dispersión normativa y de competencias en torno a la regulación de las aguas. Por lo tanto, esta herramienta nunca se ha podido consolidar apropiadamente.

Sin perjuicio de lo señalado, constituye potencialmente una oportunidad para aportar en la planificación de las ciudades, mediante una mirada integradora aportada por la EAE.

\section{Plan de Desarrollo Comunal}

Este es un instrumento establecido por la Ley 18.695 Orgánica Constitucional de Municipalidades, que tiene por objeto actuar como instrumento rector de las políticas y

17. Artículo 17 letra a) inciso final de la Ley 19.175 Orgánica Constitucional sobre Gobierno y Administración Regional. 
lineamientos a nivel comunal, incluyendo materias ambientales y para el manejo del cambio climático a nivel local.

El artículo 7 de la Ley 18.695 lo define como el instrumento rector del desarrollo en la comuna, señalando que contemplará las acciones orientadas a satisfacer las necesidades de la comunidad local y a promover su avance social, económico y cultural.

El principal efecto de este instrumento es establecer los lineamientos a seguir para el desarrollo de la comuna, por lo que, en un sistema coherente, todas las demás planificaciones dentro de dicha comuna (en salud, educación, cultura, etcétera) debiesen supeditarse a este instrumento. Por lo tanto, la planificación en materia de emplazamiento de escuelas, centros de atención de salud, plazas, entre otros, debiesen seguir los lineamientos del Plan de Desarrollo Comunal.

Este instrumento es, a escala local, una verdadera visión del espacio comunal y su desarrollo. Así, la ciudad y sus diferentes núcleos urbanos debiesen tender a integrarse según la visión, no solo urbanística, sino que también de desarrollo, económica, social y ambiental fijada desde el nivel local, y esto debe ser reflejado y retroalimentado en políticas de alcance regional y local.

\section{Regulación y planificación del territorio}

Luego de revisados los instrumentos de ordenamiento territorial estrictos, tanto normativos como indicativos, cabe preguntarse cómo esta amplia gama de instrumentos incide en la planificación de las ciudades. Ya adelantamos algunos aspectos de los instrumentos de ordenamiento territorial indicativos, pero lo más relevante son los normativos, que vienen a incidir de manera directa y vinculante sobre los centros urbanos.

En este contexto, la LGUC señala en su artículo 27 que la planificación urbana es «el proceso que se efectúa para orientar y regular el desarrollo de los centros urbanos en función de una política nacional, regional y comunal de desarrollo socioeconómico. [...] Los objetivos y metas que dicha política nacional establezca para el desarrollo urbano serán incorporados en la planificación urbana en todos sus niveles».

Luego, la LGUC pasa a describir los instrumentos de planificación territorial que revisamos en la tercera sección de este artículo, pero no profundiza o aclara el nivel de vinculación entre ellos. En este contexto, podemos entender que la planificación del territorio se basa en una serie de normas regulatorias que definen las posibles opciones de desarrollo dentro de un territorio determinado, pero que escasamente puede ser entendida como una verdaderamente planificación. La planificación territorial significa prospectar el desarrollo y crecimiento de las ciudades, mientras que la regulación únicamente define las restricciones a los proyectos y los requisitos que deben cumplir. De este modo, la planificación requiere un pensamiento estratégico sobre la ciudad, mientras la regulación solamente condiciona su crecimiento. 
Por lo tanto, podemos observar un primer aspecto que nos limita en cuanto a la forma de abordar materias de cambio climático dentro de la ciudad, toda vez que los instrumentos de planificación territorial en Chile constituyen instrumentos de regulación y no de planificación urbana. Ello limita la incidencia de medidas a adoptar para reducir la vulnerabilidad de las ciudades y también mitigar los efectos del cambio climático.

Lamentablemente, muchas veces los instrumentos de planificación territorial no tienen una interacción adecuada respecto a los múltiples usos del territorio. Tampoco suele existir una relación armónica entre dichos instrumentos y los instrumentos indicativos revisados en la sección anterior. De esta manera, encontramos una gran variedad de instrumentos que inciden en el territorio, y que pueden superponerse, $o$ incluso actuar descoordinadamente. Un ejemplo que ya fue señalado previamente es la desconexión que existe en la relación de lo urbano y lo rural, que significa perniciosos efectos para medidas efectivas en esta materia. ${ }^{18}$

Por lo anterior, cabe preguntarse qué instrumento permite armonizar la gran variedad de iniciativas en un mismo territorio, considerando que el cambio climático es un fenómeno que requiere ser abordado con una mirada intersectorial y trasversal.

En este escenario, surge la Evaluación Ambiental Estratégica como una herramienta que permite dar una mirada estratégica a la multiplicidad de instrumentos que influyen sobre las ciudades (sin olvidar la retroalimentación que existe con el territorio rural), propiciando un proceso que permita implementar una planificación que aborde la variable climática desde la fase de diseño del instrumento, e incorporándose en cada una de las etapas del proceso.

\section{La Evaluación Ambiental Estratégica y su rol en la incorporación de la variable climática en la planificación urbana}

\section{Concepto y evolución}

En palabras de María Rosario Partidário, la Evaluación Ambiental Estratégica (EAE) «es un instrumento estratégico que ayuda a crear un contexto de desarrollo que apunta a la sustentabilidad, mediante la integración de las cuestiones sobre ambiente y sustentabilidad en la toma de decisiones y la evaluación de opciones de desarrollo a la luz de las condiciones de contexto» (MMA, 2015: 13).

Los primeros antecedentes de este instrumento surgen en Estados Unidos y en los países que actualmente forman la Unión Europea. Es particularmente relevante su

18. El establecimiento del límite urbano como herramienta regulatoria, impide que se desarrolle un ordenamiento fuera los límites fijados en el Plan Regular Comunal, por lo que actividades relacionadas estrictamente a los núcleos urbanos, pero fuera de sus límites, se basan en reglas diferentes a las medidas que se pueden imponer dentro del límite urbano. 
punto de partida en la primera Ley Nacional de Política Ambiental (National Environmental Policy Act, NEPA) de Estados Unidos dictada en el año 1969, la que exigió la realización de informes sobre las consecuencias ambientales de acciones federales o de actividades que requirieran permisos o autorizaciones federales (Cordero Quinzacara y Vargas Delgado, 2016: 1.032).

Este instrumento supera la noción de evaluación ambiental de proyectos y actividades susceptibles de causar impacto ambiental, que ha sido una herramienta muy útil en la gestión ambiental, pero que evidentemente tiene un alcance acotado que no permite una planificación que considere opciones de desarrollo, sino más bien, vela porque el proyecto o actividad cumpla la normativa ambiental y mitigue, repare o compense sus impactos.

Originalmente, la Ley 19.300 contemplaba a los instrumentos de planificación territorial dentro de las tipologías de proyectos o actividades susceptibles de causar impacto ambiental enumerados en su artículo 10 y que, por tanto, debían ingresar al Sistema de Evaluación de Impacto Ambiental (SEIA), ya sea por medio de una Declaración de Impacto Ambiental (DIA) o un Estudio de Impacto Ambiental (EIA), dependiendo de si se generaban algunos de los efectos que el artículo 11 de Ley 19.300 establece (Carrasco Quiroga, 2012: 430).

Luego, mediante la Ley 20.417, que creó el Ministerio del Medio Ambiente, el Servicio de Evaluación Ambiental y la Superintendencia del Medio Ambiente, el legislador eliminó a los instrumentos de planificación territorial del listado del artículo 10, e introdujo la Evaluación Ambiental Estratégica para evaluar los instrumentos de ordenamiento territorial, y los planes y políticas de manera integral y con un enfoque estratégico.

A mayor abundamiento, en la historia de la Ley 20.417 queda de manifiesto que el objeto de la EAE era anticipar los eventuales efectos ambientales adversos asociados o que puedan derivarse de la definición de una determinada política o plan y de ese modo, considerar la prevención o mitigación de tales efectos o los mecanismos para evitar la generación de efectos ambientales acumulativos (BCN, 2010).

En este contexto, se incorporó un nuevo instrumento de gestión ambiental a la Ley 19.300, definiéndolo su artículo 2 letra i) bis, como el procedimiento realizado por el Ministerio sectorial respectivo, para que se incorporen las consideraciones ambientales del desarrollo sustentable al proceso de formulación de las políticas y planes de carácter normativo general, que tengan impacto sobre el medio ambiente o la sustentabilidad, de manera que ellas sean integradas en la dictación de la respectiva política y plan, y sus modificaciones sustanciales.

Por otra parte, el artículo 2 del Decreto Supremo 32, de 2015, del Ministerio de Medio Ambiente, que aprobó el Reglamento para la Evaluación Ambiental Estratégica, establece que su objetivo es la incorporación de consideraciones ambientales del desarrollo sustentable al proceso de formulación de las políticas, planes e instrumentos de ordenamiento territorial que la ley establece. 
A partir de las definiciones anteriores, vemos que la EAE es una auténtica metodología para incorporar objetivos de desarrollo sustentable en instrumentos a los cuales se aplica.

\section{Ámbito de aplicación}

El artículo 7 bis de la Ley 19.300 dispone:

Se someterán a EAE las políticas y planes de carácter normativo general, así como sus modificaciones sustanciales, que tengan impacto sobre el medio ambiente o la sustentabilidad, que el Presidente de la República, a proposición del Consejo de Ministros, decida.

En todo caso, siempre deberán someterse a EAE los planes regionales de ordenamiento territorial, planes reguladores intercomunales, planes reguladores comunales y planes seccionales, planes regionales de desarrollo urbano y zonificaciones del borde costero, del territorio marítimo y el manejo integrado de cuencas o los instrumentos de ordenamiento territorial que los reemplacen o sistematicen.

En la transcripción del artículo en comento queda de manifiesto que la EAE es voluntaria para las políticas y planes de carácter normativo general, mientras que es obligatoria para los instrumentos de planificación territorial y los de ordenamiento territorial revisados en la sección anterior (Plan Regional de Ordenamiento Territorial, Plan Regulador Intercomunal, Plan Regulador Comunal, Plan Seccional, Zonificación de Uso de Borde Costero, y Manejo Integrado de Cuencas). Esto es de gran relevancia, puesto que los instrumentos que deben someterse obligatoriamente al procedimiento de la EAE son de carácter eminentemente territorial, y en ausencia de una herramienta como esta, carecen de mecanismos de vinculación o coordinación, aun cuando se circunscriban sobre los mismos territorios.

En este sentido, los instrumentos que planifican las ciudades siempre deberán contar con EAE. Asimismo, los instrumentos de ordenamiento territorial indicativos, que pueden incidir en esta planificación al tenor de lo estudiado, deben someterse a este proceso. Desde luego, sería deseable que las políticas (al menos las que inciden sobre el territorio) también se sometieran a EAE, pero esto es algo que abordaremos en la última sección de este artículo, y ahora nos enfocaremos en los instrumentos descritos.

\section{Rol e importancia de la EAE}

Nuestro país ha hecho importantes esfuerzos en materia de gestión climática, que se relacionan con una multiplicidad de instrumentos destinados a mitigar los gases de efecto invernadero y a fomentar la adaptación del territorio a las consecuencia del cambio climático. Entre ellos encontramos el Plan de Acción Nacional de Cambio 
Climático 2017-2022, múltiples planes sectoriales de adaptación (biodiversidad, energía, salud, pesca y acuicultura, ciudades, silvoagropecuario, turismo, e infraestructura), la segunda versión de nuestra Contribución Determinada a Nivel Nacional y, recientemente, el Proyecto de Ley Marco de Cambio Climático.

Sin perjuicio de lo señalado, con excepción del proyecto de ley indicado (en caso de aprobarse), ninguno de los otros instrumentos tiene fuerza vinculante. De ahí la importancia de que se apruebe dicha iniciativa legal que, además, realza la importancia de los instrumentos de ordenamiento territorial y de planificación territorial en la mitigación y adaptación al cambio climático.

Por tanto, dado que los instrumentos de planificación territorial tienen fuerza vinculante para definir los usos del territorio en las ciudades, se vuelve imprescindible que sea la EAE el instrumento que incorpore la variable climática en la planificación urbana, en las múltiples manifestaciones que se han analizado previamente (esto es, tanto en instrumentos de ordenamiento territorial normativos como indicativos). En este contexto, la EAE constituye una herramienta de apoyo en el proceso de toma de decisiones, buscando incidir en la exploración de mejores opciones para el desarrollo y actuando de manera anticipada a la toma de dichas decisiones, mediante un proceso transparente y democrático (MMA, 2015: 7). Este instrumento representa un proceso sistemático, continuo y participativo que integra las consideraciones ambientales y de sustentabilidad en la formulación de decisiones estratégicas (MMA, 2015: 10). Es precisamente dicho proceso donde se abre un espacio para que se incluyan las consideraciones climáticas desde las etapas más tempranas.

$\mathrm{Al}$ respecto, cabe tener presente que en la formulación e implementación de los instrumentos de planificación territorial convergen múltiples actores con sus propios valores, preferencias y objetivos, muchas veces en conflicto o con visiones diferentes, que necesitan ser canalizados en una perspectiva común, sustentable y de largo plazo (MMA, 2015: 7). En este orden de ideas, la EAE promueve el pensamiento estratégico, agregando valor a la toma de decisiones a través del análisis de las oportunidades y los riesgos que conllevan las diversas opciones de desarrollo, así como creando una cultura estratégica en torno a la toma de decisiones, promoviendo la cooperación institucional y el diálogo entre actores (MMA, 2015: 11).

Finalmente, la EAE se transforma en un instrumento clave para pasar de la regulación del territorio a una planificación del mismo que incorpore criterios de desarrollo sustentable en general y la variable climática, en particular, mediante medidas que incidan en la adaptación y mitigación. En la siguiente sección revisaremos las oportunidades que brinda el procedimiento de EAE para estos efectos. 


\section{Procedimiento de la EAE e integración de la variable climática}

Preliminarmente, es menester tener presente ciertos conceptos propios de este procedimiento que son indispensables para determinar los alcances de la EAE. Particularmente, las opciones de desarrollo, el criterio de desarrollo sustentable y los factores críticos de decisión, conforme a lo establecido en el artículo 4 del Reglamento:

- Opciones de desarrollo son las estrategias que permitirían pasar desde la situación actual hacia la deseada, para alcanzar los objetivos planteados por la política, plan o instrumento de ordenamiento territorial.

- Criterio de desarrollo sustentable es aquel que, en función de un conjunto de políticas medioambientales y de sustentabilidad, permite la identificación de la opción de desarrollo más coherente con los objetivos de planificación y ambientales definidos por el órgano responsable en el instrumento elaborado.

- Factores críticos de decisión corresponden a aquellos temas de sustentabilidad (sociales, económicos y ambientales) relevantes o esenciales, que en función del objetivo que se pretende lograr con la política, plan o instrumento de ordenamiento territorial, influyan en la evaluación.

Aclarado lo anterior, podemos avanzar en el procedimiento de la EAE. El instrumento sometido a dicho procedimiento emana desde el órgano responsable correspondiente, que es el organismo de la Administración del Estado que impulsa la iniciativa. El rol del Ministerio del Medio Ambiente será el de orientar y colaborar en el proceso.

Según lo establecido en el párrafo 1 bis del Título II de la Ley 19.300, y en diversas disposiciones del Reglamento, la EAE consta de una etapa de diseño y una etapa de aprobación. En la etapa de diseño, el órgano responsable (de dictar la política o plan) deberá considerar los objetivos y efectos ambientales del instrumento, así como sus criterios de desarrollo sustentable. Dicho órgano deberá dictar una resolución de inicio y se abrirá un periodo de participación ciudadana para que cualquier persona, natural o jurídica, aporte antecedentes o formule observaciones respecto del proceso. Adicionalmente, se realizarán reuniones con los órganos de la Administración que participarán de la elaboración del instrumento, los que, además, formularán observaciones mediante informes.

En la etapa de aprobación se elabora el anteproyecto del instrumento que contendrá un informe ambiental que indique cómo se incorporaron las consideraciones ambientales en la toma de decisión. El informe será remitido al Ministerio del Medio Ambiente para sus observaciones. Dicho Ministerio puede indicar que se ha aplicado adecuadamente la EAE o sugerir modificar contenidos mediante la presentación de un informe ambiental complementario. Subsanadas las observaciones, el órgano 
responsable somete el instrumento y el informe ambiental a consulta pública por un plazo de treinta días para que cualquier persona pueda formular observaciones. Concluida dicha etapa, el órgano responsable dictará la resolución de término. En caso de que se hubieran realizado modificaciones sustanciales a partir de las observaciones ciudadanas, el órgano responsable enviará un informe ambiental corregido al Ministerio del Medio Ambiente, y con las observaciones de dicho Ministerio, procederá a la resolución de término.

Como queda de manifiesto de esta somera descripción de las etapas de la EAE, el órgano responsable no actúa solo, sino que es apoyado durante el proceso por el Ministerio del Medio Ambiente y por otros órganos de la Administración. Asimismo, la participación ciudadana cumple un rol preponderante, y se manifiesta tanto en la etapa de diseño como en la de aprobación.

Sin perjuicio de las etapas legales o reglamentarias de la EAE revisadas más arriba, cabe tener presente que el Ministerio del Medio Ambiente ha trabajado en guías para la implementación de este instrumento, pormenorizando las etapas conceptuales que deben seguirse. Para analizar la incorporación de la variable climática a la planificación urbana tomaremos de referencia estas etapas. Esto por razones metodológicas que permiten dar mayor claridad respecto de la incidencia de la EAE en la construcción del instrumento respectivo.

Adicionalmente, cabe tener presente que la incorporación de la variable climática mediante la EAE responde a un proceso de pensamiento estratégico que permite al órgano responsable adoptar la mejor decisión para su territorio en particular. Por tanto, el análisis se centra en el procedimiento de toma de decisión más que en las medidas concretas, pues estas últimas, como es lógico, variarán significativamente dependiendo de las realidades propias de cada territorio. Por tanto, las medidas serán distintas si las ciudades están mejor preparadas, si son más o menos propensas a desastres naturales, si presentan problemas de sequías, si son costeras, si tienen mayores problemas asociados al transporte y la contaminación atmosférica, si presentan mayores niveles de inequidad social, entre otros factores.

En este contexto, la Guía de orientación para el uso de la evaluación estratégica en Chile reconoce las siguientes etapas (MMA, 2015: 27 y ss.)

\section{Etapa de contexto y enfoque}

La EAE se focaliza en los objetivos estratégicos de la decisión, para lo que considera, entre otros, el marco del problema, el marco de gobernabilidad, los criterios de desarrollo sustentable y los factores críticos de decisión. Esta etapa es particularmente relevante para integrar la variable climática. Será desde este instante que el órgano responsable deberá plantearse cómo el instrumento de planificación territorial que se desea elaborar o modificar permitirá una adecuada adaptación del territorio a los 
impactos del cambio climático. Para ello, deberá identificar los problemas de vulnerabilidad actuales y proyectados que tiene el territorio en que se implementará el instrumento, lo que posteriormente permitirá evaluar opciones de diversas medidas que dicha herramienta puede adoptar para fortalecer la resiliencia. De manera similar, se debe enfocar el análisis en cómo el instrumento permitirá reducir las emisiones de gases de efecto invernadero.

Respecto a la gobernanza, deberá identificar actores claves en el territorio, con énfasis en aquellos que se dediquen a temas relacionados al cambio climático. Por ejemplo, a nivel regional existen los comités regionales de cambio climático, mientras que a nivel local podemos encontrar las asociaciones de municipalidades por el cambio climático.

Finalmente, los criterios de desarrollo sustentable y los factores críticos de decisión deben estar alineados a la variable climática, determinando cómo estos pasan a formar parte de criterios que permitan la sustentabilidad en el territorio o si representan variables que deben considerarse como indispensables para adoptar la decisión regulatoria.

\section{Etapa de diagnóstico ambiental estratégico}

En esta fase se determinan cuáles son las tendencias y se caracterizan los factores críticos de decisión. Por tanto, para efectos de integrar la variable climática, se deben considerar los factores descritos en la fase anterior y luego aportar información clave y sintética que permita analizar el comportamiento y tendencias de esos factores (MMA, 2015: 45).

Por tanto, si se estableció como factor la disponibilidad de agua, se deberá tener información válida de la disponibilidad de dicho recurso, así como las presiones a los que se ve enfrentado en el presente y en el futuro.

\section{Etapa de evaluación y directrices}

En esta etapa se definen las opciones de desarrollo, se evalúan sus efectos ambientales (riesgos y oportunidades), y se formulan las directrices de gestión, de planificación y de gobernabilidad (MMA, 2015: 47). Las opciones de desarrollo son los distintos caminos viables para alcanzar los objetivos ambientales y de sustentabilidad en el marco de los propósitos del proceso de decisión. Estas opciones ayudan a transitar desde la situación actual hacia aquello deseado por la decisión, según los objetivos buscados en el largo plazo (MMA, 2015: 47).

Por tanto, esta fase construye sobre lo analizado en las etapas anteriores, generando diversas opciones de desarrollo que deben considerar los riesgos y oportunidades que presenta cada opción. Es precisamente en esta etapa donde se debe optar por la 
opción que permita alcanzar las metas planteadas, disminuyendo los riesgos y potenciando las oportunidades, de manera de propender a ciudades menos vulnerables y más resilientes.

\section{Etapa de seguimiento}

En esta fase se define el seguimiento o acompañamiento de los resultados y recomendaciones del proceso de EAE, con el objetivo de ejercer un control sobre los resultados de desempeño y conformidad del instrumento, y abordando los problemas inesperados que surjan durante el proceso de implementación (MMA, 2015: 50).

En esta etapa podemos ver si las medidas de mitigación y adaptación en el territorio están comportándose de acuerdo con lo anticipado o si presentan alteraciones por elementos no analizados o que se comportaron de manera diferente a la esperada. Para realizar un seguimiento adecuado se requieren indicadores que permitan comprobar el grado de implementación de las medidas y su efecto en el territorio.

\section{Etapa continua}

Esta etapa se desarrolla de forma permanente durante todo el proceso de la EAE. Abarca la inclusión de actores clave, la sincronización de procesos de decisión y de EAE, los ajustes de las necesidades de información y los ajustes en la programación de la EAE (MMA, 2015: 52).

En definitiva, esta etapa continua y transversal se implementa de manera constante para velar por la adecuada toma de decisiones y participación de los actores clave. Todo lo anterior, con el propósito de propender a la mejor decisión sobre el territorio.

De la revisión de las distintas etapas de la EAE, podemos percatarnos de la gran incidencia que esta puede tener a la hora incorporar la variable climática. Desde el momento en que existe una mirada estratégica sobre la ciudad, integrando a los actores interesados, con participación de diversos órganos de la Administración y con etapas claras e integradoras, se aumenta de manera exponencial las posibilidades de tener instrumentos eficientes, coherentes y coordinados.

La EAE permite que exista una visión común que se vea reflejada en los instrumentos a aplicar en un mismo territorio, en sus diferentes escalas (barrial, comunal, metropolitano o regional e incluso nacional), pues hasta antes de la EAE, tales instrumentos eran elaborados independientemente por cada uno de los órganos responsables. Sin embargo, con la irrupción de este instrumento de gestión ambiental, el Ministerio del Medio Ambiente ejerce un rol colaborador y orientador, contribuyendo a lograr una planificación del territorio conforme a directrices comunes y una mirada integradora. 


\section{Desafíos y oportunidades de la EAE en un contexto de cambio climático}

\section{Oportunidades}

\section{Contribuir a lograr una verdadera planificación de las ciudades}

Como vimos en este trabajo, los instrumentos de planificación territorial regulan más que planifican el espacio urbano. Para lograr la planificación será necesario interrelacionar los distintos instrumentos que aplican en el territorio, así como un involucramiento de todos los actores relevantes. La EAE puede convertirse en una herramienta coordinadora de diferentes iniciativas sobre los centros urbanos, respetando las singularidades locales para su debida implementación.

Conforme a lo analizado en este artículo, la planificación se destaca por su dinamismo y la necesidad de coordinar las actividades, además de operar en varios niveles espaciales interrelacionados entre sí. En ese contexto, las políticas que incidan sobre el territorio serán de gran relevancia como instrumentos orientadores. Por lo anterior, la EAE debe reconciliar conflictos de intereses y presentar opciones de desarrollo que se puedan adaptar a las circunstancias actuales sin comprometer negativamente el futuro, logrando que la planificación sea una actividad que se oriente hacia un resultado en el tiempo y constituya un proceso continuo que permita una asignación eficiente de los recursos estatales, de manera de alcanzar los objetivos y metas propuestos.

Asimismo, la ciudad como objeto de regulación debe relacionarse con su territorio de manera armónica. La mera planificación de lo urbano resulta insuficiente; debe también recoger sus interacciones con lo rural y con aquellos espacios territoriales vinculados a la ciudad pero que escapan de su reglamentación.

El caso español es paradigmático. Barcelona es la ciudad pionera en este ámbito desde que en 1987 pusiera en marcha su Plan Estratégico Económico y Social. A partir de esta iniciativa se produjo una primera generación de planes estratégicos, cuyos exponentes más significativos fueron los de Bilbao Metropolitano (1992), Málaga (1992), Valencia (1995) o Zaragoza (1998). Las características que se repitieron en todos estos procesos fueron la implicación de los principales agentes económicos y sociales de la ciudad, que trabajaron de forma consensuada, y el afán por mejorar la calidad de vida de los ciudadanos. ${ }^{19}$

En este sentido, la EAE combina esfuerzos territoriales, económicos y sociales en un mismo territorio con objetivos comunes y claros para su implementación. ${ }^{20}$

19. Véase Ebrópolis, «Planificación Estratégica en España», disponible en https://bit.ly/3yWDhel.

20. Las ciudades y territorios con planificación estratégica intentan anticiparse a lo que va a suceder, planteando escenarios futuros. Después de pasar por planes estratégicos de distinta generación, distintos cambios de gobierno y resistir a la velocidad con la que cambian las cosas, en la actualidad las 


\section{Alcanzar una participación ciudadana más eficaz y eficiente}

Durante muchos años la inclusión de actividades participativas en el diseño o los ajustes de instrumentos de planificación territorial han dependido de la visión sectorial, regional o comunal de los diferentes órganos de la Administración u órganos responsables de los respectivos instrumentos, por cuanto su valoración se ha visto limitada al grado de incidencia o conflictividad que pudiesen suponer las decisiones sobre el territorio y su planificación (Minvu, 2018).

Sin embargo, actualmente el Reglamento de la EAE ha abordado la consulta pública tanto en la etapa de diseño del instrumento como en la etapa de su aprobación. La participación ciudadana es amplia, ya que cualquier persona puede formular observaciones, y el órgano responsable deberá analizar dichas observaciones y señalar en la resolución de término la forma en que han sido consideradas.

En este mismo sentido, los cambios normativos establecidos en los últimos años, a través de la dictación de la Ley 20.500 sobre Asociaciones y Participación Ciudadana en la Gestión Pública, la Política Nacional de Desarrollo Urbano (2014) y la Ley 21.078 sobre Transparencia del Mercado del Suelo e Impuesto al Aumento del Valor por Ampliación del Límite Urbano, entre otras, han contribuido a generar una incorporación sistemática y fundamentada de la opinión de los diversos actores sociales como parte de un proceso democrático que enriquezca la política pública en materia urbana y provea de una base de validación de las propuestas de planificación territorial para facilitar su aprobación y entrada en vigor.

Sin perjuicio de estos avances, aún quedan aspectos por mejorar, particularmente en el involucramiento significativo de la ciudadanía. La participación de las personas es crucial. Una reforma de una política o un plan serán mucho más efectivos cuando los valores, puntos de vista, opiniones y conocimiento de la ciudadanía queden reflejados en el proceso. Para quien toma la decisión, la participación activa y efectiva de las personas le otorgará un mayor grado de confianza para tomarla, y disminuirá el riesgo de una decisión con potenciales resultados desfavorables (OCDE, 2007: 42-44).

La evaluación de las políticas públicas, de los planes y normas, debemos entenderla como una necesidad que plantea la buena gobernanza al momento de adoptar decisiones estratégicas, que van a tener una importante incidencia social y cuyos alcances deben ser medidos antes, durante y después de su implementación en todas sus dimensiones, a fin de garantizar la mayor eficiencia y eficacia para alcanzar los objetivos que se ha planteado la autoridad.

ciudades han actualizado su pensamiento estratégico para adaptarse a esta coyuntura mundial de cambio permanente. Se trabaja más con elementos intangibles y se viene hablando de la articulación de la planificación con la gestión estratégica y su concepción como instrumento de gobernanza. 
En este mismo sentido, vale mencionar que la Directiva Europea 2001/42/EC para la Evaluación Ambiental Estratégica es aplicada para planes públicos y programas, y la consulta pública es considerada la característica fundamental de los procesos de evaluación ambiental (Comisión Europea, 2004).

\section{Desafíos}

Seguimiento de los indicadores y estándares fijados en los instrumentos sujetos a la EAE

Dentro de la EAE, se incluyen criterios e indicadores de seguimiento, los que, según el artículo 7 quáter de la Ley 19.300, están «destinados a controlar la eficacia del plan o política, y los criterios e indicadores de rediseño que se deberán considerar para la reformulación de dicho plan o política en el mediano o largo plazo». Esta herramienta adquiere la mayor de las relevancias, pues uno de los elementos necesarios es el seguimiento en la implementación del instrumento, para medir su efectividad en el tiempo.

A mayor abundamiento, el literal e) del artículo 4 del Reglamento define los criterios de seguimiento como el «conjunto de elementos de análisis destinados al conocimiento y evaluación, dentro de un plazo determinado, de los resultados de la implementación de una política, plan o instrumento de ordenamiento territorial sometido a Evaluación Ambiental Estratégica». Por tanto, son los indicadores los que nos permitirán determinar si el instrumento está teniendo la incidencia esperada en el territorio al momento de evaluarse. Estos indicadores permitirán adoptar las medidas correctivas que sean necesarias para alcanzar los objetivos del instrumento. Un excelente ejemplo en esta materia es la Política Nacional de Energía 2050, ${ }^{21}$ que cuenta con criterios de seguimiento claros, incluyendo el cambio climático dentro de sus consideraciones.

El anterior es un ejemplo exitoso, pero también podemos encontrar aquellos en que han fijado indicadores que no han sido monitoreado de manera adecuada, ya sea por falta de seguimiento del órgano responsable, por problemas en la estructura de gobernanza o por falta de coordinación con otros órganos de la Administración, entre otros factores. Son estos problemas los que deben ser abordados para seguir fortaleciendo este instrumento de gestión ambiental.

21. Los criterios de seguimiento son: 1) baja de las emisiones; 2) uso de energías renovables; 3) cambio climático; 4) calidad ambiental; 5) beneficios sociales; 6) pobreza energética; 7) conflictos sociales; 8) innovación en energía; 9) servicios ecosistémicos; 10) costo de la energía; 11) seguridad en el suministro energético; 12) conservación de la biodiversidad y servicios ecosistémicos; 13) percepción ciudadana; 14) imagen-país; 15) ciudades sustentables; y 16) resiliencia del sector energético. Cada criterio tiene sus propios indicadores, lo cual permite desarrollar factores de trazabilidad. 
Incorporar la EAE de manera obligatoria en las políticas, planes o programas aplicables sobre el territorio

Existe una jerarquía de niveles en la toma de decisiones, que comprende proyectos, programas, planes y políticas. Lógicamente, las políticas les dan forma a los planes, programas y proyectos subsiguientes que ponen en práctica estas políticas. Las políticas están en el pináculo de la jerarquía de toma de decisiones. A medida que uno desciende por el entramado jerárquico, de políticas a proyectos, cambia la naturaleza de las decisiones que se tienen que tomar, como también la naturaleza de la evaluación ambiental requerida. La evaluación en el nivel de políticas tiende a tratar con propuestas más flexibles y un abanico más amplio de escenarios. La evaluación en el nivel de proyectos habitualmente tiene especificaciones bien definidas y delimitadas. Las políticas, planes y programas son de esta manera más estratégicos, pues definen la dirección o enfoque general que debe seguirse para lograr los objetivos amplios. En dicho ámbito, la EAE tiene un nivel de incidencia muy significativo.

Como se vio en su oportunidad, conforme al artículo 7 bis de la Ley 19.300, el sometimiento a EAE de las políticas y planes de carácter normativo general (así como sus modificaciones sustanciales), que tengan impacto sobre el medio ambiente o la sustentabilidad, es de carácter voluntario. Por tanto, para que dichas políticas o planes sean sometidos a EAE será necesario que el ministerio a cargo del instrumento en cuestión solicite al Consejo de Ministros para la Sustentabilidad (CMS) que proponga al Presidente de la República someter dicho instrumento a EAE y que este último así lo disponga.

Por tanto, vemos una doble discrecionalidad. En primer lugar, la discrecionalidad del organismo sectorial de decidir si somete o no su política o programa a EAE y, en segundo lugar, la discrecionalidad del Presidente de la República, pues aun con la propuesta del CMS, el Presidente podría desestimar la solicitud.

En este contexto, nos parece preocupante que las políticas o programas que tengan impacto sobre el medio ambiente o la sustentabilidad no sean sometidos obligatoriamente a EAE. Al respecto, estimamos que al menos debiesen someterse de manera obligatoria aquellas políticas y programas que incidan directamente sobre el territorio. Esto es de toda lógica por el entramado jerárquico en la toma de decisiones que señalamos más arriba y, además, porque difícilmente se puede optar a tener instrumentos de planificación territorial pensados estratégicamente para las ciudades, cuando no cuentan con una política que les den las directrices necesarias para la planificación urbana, y esa política haya sido construida con EAE.

Sin perjuicio de lo señalado, se debe reconocer que han ido en aumento las políticas que se han sometido voluntariamente a este proceso $^{22}$ y se espera que la tendencia

22. Política Energética Nacional 2050 y su actualización, Política Nacional de Ordenamiento Terri- 
continúe. No obstante, no debiese quedar entregado a las autoridades de turno, sino más bien ser definido por el legislador.

Finalmente, y respecto a la importancia de que algunas políticas y estrategias se sometan obligatoriamente a EAE, es interesante mencionar la experiencia en el derecho comparado, particularmente con lo que sucede en Estados Unidos. A partir de la dictación de la National Environmental Policy Act, se exige que las agencias federales elaboren una Declaración de Impacto Ambiental Programática (Programatic Environmental Impact Statement) cuando deseen establecer una política, plan o programa que afecte significativamente la calidad del medio ambiente en relación con las personas en un determinado territorio, exigiendo una declaración detallada sobre los impactos ambientales de la medida propuesta, cualquier eventual efecto negativo que no puede ser evitado si la propuesta es implementada, alternativas de acciones, la relación entre el uso del medio ambiente y la productividad a corto y largo plazo, y sus posibles efectos irreversibles. ${ }^{23}$

\section{Conclusiones}

Chile es un país altamente vulnerable al cambio climático y sus ciudades están expuestas a los impactos de este fenómeno global. Dichos impactos incluyen el aumento de la temperatura, olas e islas de calor, daños en infraestructura, desastres naturales, escases de bienes y alimentos, inundaciones, entre muchos otros fenómenos. Adicionalmente, los impactos del cambio climático tienen la potencialidad de afectar la salud de las personas y exacerbar las consecuencias de las pandemias como la que actualmente enfrenta el mundo.

Para hacer frente a la situación descrita es imprescindible planificar las ciudades de manera de reducir la vulnerabilidad, aumentar la resiliencia y, además, reducir la emisión de gases de efecto invernadero. Para lograrlo se requiere transitar de la regulación del territorio hacia su planificación. Para ello, será necesario una interacción entre los instrumentos de planificación territorial, los OIT indicativos que inciden en los centros urbanos, y las políticas y estrategias que tienen aplicación territorial e interactúan con los instrumentos descritos. Nuestro análisis realzó la importancia de los instrumentos de planificación territorial, pues serán estos los que regulen la ciudad con carácter vinculante, pero será necesaria la interacción de todos los instrumentos para una adecuada planificación.

En este contexto, la EAE se presenta como el instrumento de gestión ambiental

torial, Política Nacional de Minería, y Actualización de la Política Nacional de Uso del Borde Costero.

23. National Environmental Policy Act (NEPA), Sec. 102 [42 USC $\$ 4332$ ], disponible https://bit. ly/3psgYKm. 
capaz de armonizar e integrar diversas visiones y escalas territoriales, de manera de contribuir a lograr una planificación coherente y con proyección a futuro. De la revisión de esta herramienta, pudimos observar cómo se manifiesta con gran intensidad en las etapas iniciales de diseño del instrumento, acompañando todo el proceso de elaboración y aprobación, con repercusiones que se extienden hasta su implementación, en la etapa de seguimiento.

En este escenario, podemos apreciar el rol fundamental que cumple la EAE para integrar la variable climática en la planificación de las ciudades. Será mediante esta herramienta que se podrá lograr un pensamiento estratégico que acompañe al órgano responsable en definir la mejor opción de desarrollo, considerando los criterios de desarrollo sustentable y los factores críticos de decisión, en ambos casos, asociados a la adaptación y mitigación al cambio climático.

Para lograr esta interacción, es indispensable el papel que juegan los organismos de la Administración, aportando en la discusión respecto del instrumento; el acompañamiento durante todo el proceso del Ministerio del Medio Ambiente, como colaborador y coordinador; y el involucramiento de la ciudadanía mediante las instancias dispuestas para ello, tanto en la etapa de diseño como en la de aprobación. Todas estas interacciones se hacen posible en el contexto de la EAE, actuando desde las etapas más tempranas, con una mirada a largo plazo, con flexibilidad para adaptarse al instrumento en cuestión, y con transparencia para una participación adecuada de la ciudadanía, ente otras características.

Por tanto, la integración de la variable climática se da en el marco de una metodología que define cómo se deben adoptar las decisiones que permitan disminuir la vulnerabilidad de las ciudades y, a la vez, convertirse en un actor relevante en la mitigación de gases de efecto invernadero, que son los que, precisamente, ocasionan dicha situación de vulnerabilidad. En consecuencia, el foco está en el proceso de toma de decisiones y no en las medidas en concreto que, como se dijo, dependerán de las circunstancias territoriales de la ciudad en que se aplicará la planificación urbana.

Finalmente, y no obstante los grandes avances de la EAE, quedan desafíos respecto al seguimiento de los instrumentos sometidos a dicho procedimiento, así como una aplicación más extensiva a políticas y estrategias que orienten y articulen otros instrumentos a una escala más acotada.

La EAE también presenta oportunidades y desafíos en materia de participación ciudadana. Es de esperar que el involucramiento de los actores relevantes siga creciendo y que se propicien mecanismos que permitan un involucramiento activo y significativo. Esto redundará en la elaboración de un mejor instrumento que, con el acompañamiento de la EAE, sin duda se convertirá en un mecanismo que permita planificar la ciudad y fortalecer su resiliencia, redundando en una mejor calidad de vida para las personas y en un aporte en la lucha contra un fenómeno global que es responsabilidad de todos. 


\section{Referencias}

Minvu, Ministerio de la Vivienda y Urbanismo de Chile (2018). «Anexo 1. Estrategia de participación». En Manual de contenidos y procedimientos para la aplicación de la evaluación ambiental estratégica en los instrumentos de planificación territorial (pp. 101-186). Disponible en https://bit.ly/32qoN7F.

Aylwin Fernández, Martín y Robert Currie Ríos (2020). Desafíos para las empresas en un escenario de cambio climático: ¿El fin del business as usual? Revista de Derecho Ambiental, 13: 7-37. Disponible en https://bit.ly/3FGhvy6.

BCN, Biblioteca del Congreso Nacional de Chile (2010). Historia de la Ley 20.417, que crea el Ministerio, el Servicio de Evaluación Ambiental y la Superintendencia del Medio Ambiente. Disponible en https://bit.ly/3oYKYnR.

Carrasco Quiroga, Edesio (2012). «Evaluación ambiental estratégica y procedimiento administrativo: legalidad, supletoriedad y funcionalidad». Revista Actualidad Jurídica, 25: 421-438.

Comisión Europea (2004). Aplicación de la Directiva 2001/42 relativa a la evaluación de los efectos de determinados planes y programas en el medio ambiente. Disponible en https://bit.ly/3qpHG5F.

Comité Científico COP25 (2019). Ciudades y cambio climático en Chile: Recomendaciones desde la evidencia científica. Santiago: Comité Científico COP25 y Ministerio de Ciencia, Tecnología, Conocimiento e Innovación. Disponible en https:// bit.ly/zqshreX.

Cordero Quinzacara, Eduardo e Iris Vargas Delgado (2016). "Evaluación Ambiental Estratégica y planificación territorial. Análisis ante su regulación legal, reglamentaria y la jurisprudencia administrativa». Revista Chilena de Derecho, 43 (3): 1.031-1.056.

Dirección Meteorológica de Chile (2020). Informe técnico. Olas de calor en Chile. Una nueva metodología para el estudio y monitoreo de los eventos de altas temperaturas. Santiago: Oficina de Servicios Climatológicos, Dirección Meteorológica de Chile. Disponible en https://bit.ly/3FFZIXO.

EPA, United States Environmental Protection Agency (2019). Air quality and climate change research. Disponible en https://bit.ly/3Hp6gLo.

Gobierno de Chile (2016). Informe Nacional Hábitat III. Disponible en https://bit. ly/3JlqEhB.

-. (2018). Plan de Adaptación al Cambio Climático para Ciudades 2018-2022. Anteproyecto probado por el Consejo de Ministros para la Sustentabilidad. Disponible en https://bit.ly/3yVzqhA.

IPCC, Intergovenmental Panel on Climate Change (2018). Climate Change 2014: Impacts, Adaptation, and Vulnerability. 8 Urban Areas. Disponible en https://bit. ly/32kvv2a. 
MMA, Ministerio del Medio Ambiente de Chile (2015). Guía de orientación para el uso de la evaluación estratégica en Chile. Santiago: Oficina de Evaluación Ambiental del Ministerio del Medio Ambiente. Disponible en https://bit.ly/3qovPVr.

-. (2020). Contribución determinada a nivel nacional (NDC) de Chile. Actualización 2020. Santiago: Ministerio del Medio Ambiente de Chile. Disponible en https:// bit.ly/3qq PUKF.

-. (2020). Plan de Acción Nacional de Cambio Climático 2017-2022. Anteproyecto en consulta pública. Disponible en https://bit.ly/3Ept4Z6.

OCDE, Organización para la Cooperación y el Desarrollo Económicos (2007). La Evaluación Ambiental Estratégica. Una guía de buenas prácticas en la cooperación para el desarrollo. Disponible en https://bit.ly/3epuSgS.

OPS, Organización Panamericana de la Salud (2019). Ola de calor y medidas a tomar. Revisión preliminar. Washington: OPS. Disponible en https://bit.ly/3FHBblj.

Pérez Castillo, Claudio y Yukio Shinomi (2009). Manejo integral de cuencas hidrográficas. Conceptos básicos. Disponible en https://bit.ly/3Fueocs.

Precht Rorris, Alejandra, Sonia Reyes Paecke y Carola Salamanca Gatica (2016). El ordenamiento territorial en Chile. Santiago: Ediciones Universidad Católica de Chile.

Public Health England (2015). Heatwave plan for England. Making the case: The impact of heat on health, now and in the future. Londres: Public Health England. Disponible en https://bit.ly/3Jjb4Da.

UNDRR, Oficina de Naciones Unidas para la Reducción del Riesgo de Desastres (2015). Marco de Sendai para la Reducción del Riesgo de Desastres 2015-2030. Disponible en https://bit.ly/3emo8GP.

Wu, Xiao, Rachel Nethery, Benjamin Sabath, Danielle Braun y Francesca Dominici. (2020). "Air pollution and covid-19 mortality in the United States: Strengths and limitations of an ecological regression analysis». Science Advances, 6 (45). DOI: 10.1126/sciadv.abd4049.

\section{Sobre los autores}

Robert Currie Ríos es máster en Derecho Ambiental (LL.M.) de la Universidad de Columbia, Estados Unidos. Profesor de Derecho Ambiental de la Facultad de Derecho de la Universidad Andrés Bello (dirección postal: Bellavista 0121, Providencia, Santiago). Miembro del Centro de Investigación para la Sustentabilidad de la misma universidad. Profesor del Magíster en Derecho Ambiental de la Universidad del Desarrollo. Jefe del Departamento de Legislación y Regulación Ambiental del Ministerio del Medio Ambiente. Su correo electrónico es r.currie@udd.cl. (D) https://orcid. org/0000-0001-7351-801X. 
Gonzalo Pérez González es máster en Derecho Ambiental (LL.M.) de la Universidad de California UC Berkeley, Estados Unidos. Consultor Legal para el Programa de las Naciones Unidas para el Desarrollo (PNUD). Su correo electrónico es gonzalo.perez@berkeley.edu. (D) https://orcid.org/oooo-0002-9187-4912. 
La Revista de Derecho Ambiental, del Centro de Derecho Ambiental de la Facultad de Derecho de la Universidad de Chile, es un espacio de exposición y análisis en el plano académico del derecho ambiental. Su contenido se presenta a través de doctrina, jurisprudencia y recensiones, y aborda diversas materias relacionadas con la gestión, institucionalidad y herramientas de protección ambiental y desarrollo sustentable. Se presentan artículos de diferentes autores y autoras en los que se analizan y abordan casos y temas jurídico-ambientales de creciente interés y actualidad.

\author{
DIRECTORA \\ Valentina Durán Medina \\ EDITORES \\ Jorge Ossandón Rosales \\ y Antonio Pulgar Martínez \\ SITIO WEB \\ revistaderechoambiental.uchile.cl \\ CORREO ELECTRÓNICO \\ revistada@derecho.uchile.cl \\ LICENCIA DE ESTE ARTÍ́CULO \\ Creative Commons Atribución Compartir Igual 4.o Internacional
}

La edición de textos, el diseño editorial

y la conversión a formatos electrónicos de este artículo

estuvieron a cargo de Tipográfica

(www.tipografica.io) 